\title{
Exploring the Connections Between Refugees, Places and Social Capital A Case Study of Khirkhi Extension
}

Milan SHARMA, TISS Mumbai, India

\begin{abstract}
The paper's aim is to understand how modern refugees recreate lives in a foreign city. It discusses the place building efforts of the refugees, the roles and importance they possess for the refugees, natives, and society. Furthermore, it looks at places in a globalised world that acts as preservers of culture and identity. It also tries to understand the role played by social capital in enabling place building. It establishes a connection between unauthorised colonies and refugees in New Delhi and comments on the changing nature of the influence refugees wield now. The paper is part of the larger realm of studies which touches upon the concepts of migration, urbanisation, and globalisation.
\end{abstract}

\section{Keywords}

Refugees, Place-building, Social Capital, Unauthorized colonies.

\section{Introduction}

The world is witnessing an enormous scale of displacement greater than in any other era. According to United Nations High Commissioner for Refugees (UNHCR), 79.5 million people worldwide have been displaced forcibly by $2019 .{ }^{1} 67$ percent of these displaced people come from five countries: the Syrian Arab Republic, Venezuela, Afghanistan, South Sudan, and Myanmar. Further, 86 percent of displaced people are hosted by the developing countries. ${ }^{2}$ India since the time of independence continues to be one such country, providing safe and secure environment for refugees in cities. It is maintained that the present displacement challenge is unique and has a distinct urban connection. Displaced people are moving to cities in large numbers due to multiple reasons, but the most significant and foremost reason is that cities offer more opportunities to make a better life than camps (where refugees are stationed). Delhi, the national capital of India, due to its geographical and political significance has remained one such city housing refugees in India. The city has housed partition refugees (1947), Tibetans (1960s), Sikh, Hindu and Christian Afghans (1990s) and still welcomes refugees from Somalia, Myanmar, Pakistan, and Afghanistan. Each of these groups have initiated reterritorialization efforts to make a home for themselves in the new environment. As a result, these efforts have led to socio-cultural, economic, and spatial changes in the city.

Since Delhi had a history of granting asylum, it becomes imperative to understand how their influences shape the city. Studies on partition-based refugees in Delhi have attempted to uncover these influences, for instance, they bring out a clear relationship between unauthorized colonies and refugees. However, modern day refugees remain unrepresented through these studies. The aim of the paper is to understand

\footnotetext{
${ }^{1}$ UNHCR, The UN Refugee Agency, India. Figures at a Glance. Available at: https://www.unhcr.org/figures-at-aglance.html. The figure includes refugees, asylum seekers, internally displaced people, and stateless people.

${ }^{2}$ UNHCR, The UN Refugee Agency. Refugee Data Finder. Available at: https://www.unhcr.org/refugee-statistics
} 
the relationship refugees establish with the new territory and reterritorialize themselves within a neighbourhood. It also comments on the shifts that have been observed in this process. The paper's findings are located in one neighbourhood of the city called Khirkhi extension.

\subsection{Khirkhi Extension}

Khirkhi village, touted to have been made in the 1400s in the fourth city of Delhi, i.e. Jahapanah, changed dramatically post 1947 . The lands from the village were acquired by the newly independent government to initiate development activities like building houses, roads, etc. In the 1980s the city began to grow and the villagers decided to grow their surroundings as well by building houses on the common lands of the village. The new colony created by the villagers came to be known as Khirkhi extension, an uanauthroised colony. Interestingly, the colonies built by citizens without the aid and authorisation of the state are deemed unauthorised colonies in the planning framework of the government. The Delhi Development Authority (DDA) which is responsible for formulating the master plan of the city has not acknowledged these places as legitimate and keep them outside the purview of state led development by not including these colonies in the master plan. Thus, the people themselves arranged for basic infrastructure services such as water supply, electricity, sewerage, and waste management system at Khirkhi Extension.

Located in one of the prime regions of the city, the villagers developed the colony through their own efforts in the hopes of earning money through real estate development. In the 2000s, the neighbourhood witnessed development of world class infrastructure facilities such as shopping complex, court and megahospitals that led to favourable conditions for villagers to earn rental income. Due to these developments, an increasing number of migrants found work here and Khirkhi Extension provided them with cheaper housing, in comparison to other parts of the city. As a result, Khirkhi extension experienced a boom in its economy, during this time.

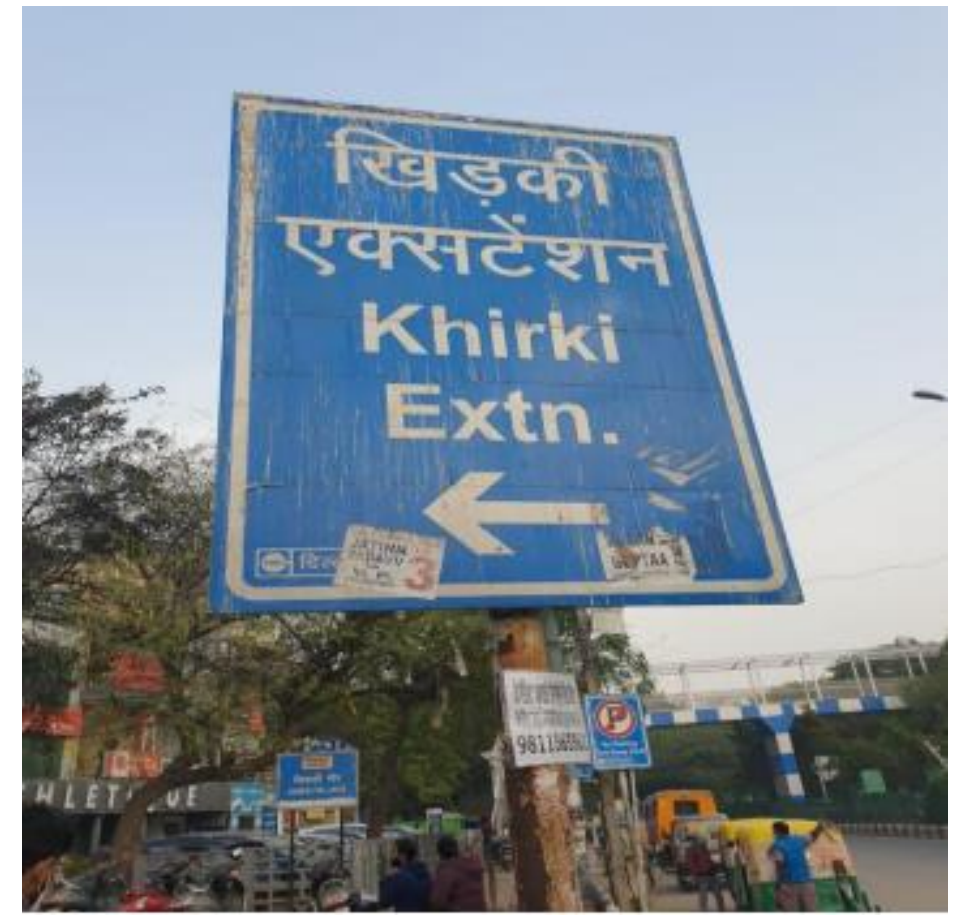

Figure 1: Entry to Khirkhi Extension where Afghan refugees live. Source: Field visit, Author.

This was also the time when refugees began to settle in the neighbourhood. They hoped that the booming economy and cheap rents would offer a sustainable lifestyle. Thus, several migrants from Bihar, Bengal, Kerala and refugees from Afghanistan, Somalia, Nigeria, and Ivory Coast find themselves in Khirkhi, recreating life in new surroundings. 
The paper focuses on the Shia Ismaili Afghan refugees in particular due to their numeric majority and influence at Khirkhi. It tries to uncover the multifaceted ways in which they reterritorialized through place building and spatial transformation. It will comment on the ways they influenced the territory. Furthermore, the paper will discuss the conflicts and power differences that are consequences of their dominant position at Khirkhi.

The paper begins with a brief introduction to the study and moves on to discussing literature review and methodology. The subsequent section discusses research findings that entails a description of places built and transformed by the refugees, their nature, roles, and impact on the neighbourhood. The concluding section of the paper tries to locate the research findings within the broader context of migration studies, urbanisation, and globalisation.

\section{Literature Review}

The section enumerates and discusses different phenomena associated with refugees in exile.

\subsection{Refugees and reterritorialization}

Partition of British India into the Republic of India and Islamic Republic of Pakistan led to large scale mass migration across the borders of the two newly created countries. Muslims deserted Indian cities while Hindus and Sikhs were forced to leave Pakistan. Millions of people suffered in the violence and riots that accompanied migration and lost their loved ones as well as material belongings. Thus, at the dawn of independence, India had a grave refugee crisis at its hands. Most refugees from Pakistan had fled to New Delhi, creating an immediate surge in the population of the city. As a result, demand for housing and other basic services also increased dramatically. The Indian state, embarked on the journey of fulfilling these needs but fell short. The refugees were tired of living in camps and had lost faith in the governance system to provide for them. Thus, through community connections and individual efforts, the refugees fulfilled their own needs. They built houses on vacant lands on the outskirts of the city and transformed them into colonies. As a result, squatters increased in the city centre and unauthorised colonies became common on the outskirts of the city. They also opened businesses and shops to earn a living.

'New markets for refugees came up. Lajpat Rai market and Karol Bagh Market came up owing to the efforts of enterprising refugees. Delhi thus came under the commercial hegemony of refugees.' (Kumari, 2013).

With the expansion of the city in the last 75 years, these colonies have become a central part of the city as important business and market hubs. The cultural and social lifestyle of Delhi changed. The Muslim culture was replaced by the Punjabi culture and lifestyle. As Singh noted:

In addition to this, there have been some interesting changes in the general lifestyle of Delhi which are worth mentioning. Urdu went into a steep decline to be replaced by spoken Punjabi. Mushairas became rare, being replaced by Kavi sammelans. Mujras patronized by the rich of all communities disappeared. Also trades like Zari, embroidery, making silver and gold leaf paper in which Muslims specialized died out. Dhabas sprang up and restaurants started serving tandoori chicken and fish, dal makhni, sarson ka saag and makai ki roti, gazar ka halwa and kulfifalooda. Wedding manner changed practices like groom coming atop white mare, women doing bhangra and brass bands playing Hindi film tunes were started.' (Singh 2001:41).

Thus, the refugees transformed Delhi into a city which was more akin to their identity, culture, and aspirations.

Similar actions were undertaken by the Tibetan refugees in the 1960s. They were provided barren lands on the outskirts of the city to set their camp by the government of India. They managed to build houses 
and shops on this land, themselves. Their intervention has resulted in a mini-Tibet in Delhi popularly known as 'Majnu ka Tila'. It acts a tourist spot for the visitors and a source of income for the refugees.

The refugees exhibit behaviours which are conducive to recreating life in a new territory. They imported their culture and identity and built houses and economy for themselves. Malkki, has recognised this process as reterritorialization. It means losing a territory and then reconstructing a new territory.

\subsection{Refugees and Places}

Two types of places are associated with refugees- Essentialist notions of places and non-essentialist notions of places. The former maintains that everyone has a particular place in the world. Those who are torn lose from their place are displaced and uprooted. The loss of place accompanies the loss of identity and culture. The latter critiques the former and argues that people are not fixed or tied to a territory. There is more mobility in the world today than before and refugees do not live in a pathological state. Losing place does not mean losing identity or culture.

"Even though people must flee, they are not torn loose from their culture, they do not lose their identity, and they do not become powerless. Refugees are not passive victims in an abnormal state of being, rather they are active agents who are able to develop strategies and thus still function socially." (Brun, 2001, 18)

These scholars emphasise on creating a separation between place, culture, and identity. These ideas have emerged in a globalised world where diasporas have created places rooted in their culture and identity within a territory that is ethnically and nationally not their own. For instance, an Indian supermarket selling Indian clothes and materials in London. Doreen Massey conceptualised this change across the world and argued that increased movement of people has created a 'global sense of place'. In a globalised world, places are not fixed rather it is a social construct. Places "are products of the society in which we live" $(1995,50)$.

Non-essentialist scholars have examined the role of memory in the creation of places by refugees. For instance, Appadurai maintains that collective memory of a group can alter social reality.

'Imagination is taking place on an individual scale, but the collective imagination of a group of people that begin to feel and imagine things together is pivotal. As groups share collective imagination, they create new social realities.' (Appadurai, 1996).

He argues that groups create Ethnospaces which reflect these memories on physical spaces.

'Ethnospaces are landscape of persons who constitute the shifting world in which we live: tourists, immigrants, refugees, exiles, guestworkers, and other moving groups and persons' (Appadurai, 1990, p. 329).

In short, he maintains that memory plays an important role in influencing places especially in the present world where more people are moving around and settling in new territory.

\subsection{Social Capital}

'Social capital is the aggregate of the actual or potential resources which are linked to possession of a durable network of institutionalized relationships of mutual acquaintance and recognition-or in other words, to membership in a which provides each of its members with the backing of the collectively owned capital, a "credential" which entitles them to credit, in the various senses of the word.' (Bourdieu, 1986, 247).

These words of Bourdieu highlight that social capital is a means by which better position and economic interests of a community or individual can be met. It also alludes to power equations that exist in society 
and how newer one keeps building up with the acquisition of social capital. Even though there is a dearth of literature on social capital and refugees, some like Zetter et al have argued that migrants acquire social capital to attain social cohesion and be part of the larger society.

\section{Methodology}

To closely analyse the lives of refugees in Delhi, the changes, and adaptations they witness in exile, the paper employs an ethnographic case study approach. The ethnographic approach is best suited as it allows the researcher to observe and be part of the lives of a desired community of people. Furthermore, Khirkhi extension is a recent neighbourhood to be inhabited by refugees from several countries. With refugees settled not more than 10 years ago, the neighbourhood provides an interesting spatial, social, political, and complex phenomenon to undertake refugee study.

The ethnographic case study method was employed using the following research tools:

1. Participant and non- participant observation

2. Semi-structured interviews

3. Oral history

4. Photographic survey

5. Documentation

Non-probability sampling was used with snowball sampling as the principal sampling method. It enabled the research to be conducted spontaneously with many refugees and residents. The method increased the chances of being engrossed within the community and its networks and thus fulfil the goal of observing the community and neighbourhood closely.

\section{Research Findings}

The Shia Ismaili Afghan is the largest refugee community in Khirkhi numbering $2600 .{ }^{3}$ They have been the most influential refugee community in the neighbourhood exemplified by the places they have created and the influences they wield. This section discusses their place-building efforts and its impact on the entire neighbourhood.

\subsection{Community and Place-Building}

Aristotle's saying that 'Man by nature is a social animal' becomes evident in the behaviour and value supposition of refugees. They create life around communities, that becomes a source of emotional and material support and safeguard their culture and identity in exile. The Ismailis across the world are united as a single community under their religious leader, His Highness Prince Aga Khan. The sustenance of community networks is an important religious and cultural practice in this sect. These networks help members assimilate and reterritorialize in a new country. In the case of Ismaili refugees at Khirkhi, community ties are of paramount importance. These networks help find homes and jobs in the new place. It also ensures that the new arrivals get acquainted with the laws and procedures followed in the new country and other members of their group. The community acts as metaphorical box where the individual members put themselves in and makes it a root of their identity. This community has rigid rules and exclusive membership that is useful in distinguishing them from other refugee groups. The Ismailis from Afghanistan maintain this rigidity and exclusivity because of strong intracommunity ties and a lack of understanding and commonality with other refugee groups like the Somalis or with the locals, i.e., Indians. The exclusivity also helps them retain and practice their religious and cultural rituals without fearing a clash of cultures with the locals or losing their individuality due to excessive intermingling with

\footnotetext{
${ }^{3}$ as per the Shia Ismaili council's estimations.
} 
other communities. It is important to note that the Ismailis do mix with other communities and engage in secular rituals, however, when it comes to their identity and religion, their activities and practices become exclusive, open only to those who identify themselves as a Shia Ismaili.

Naturally, the community engages in many activities which stem from their culture and religion. These include everyday practices such as prayer or occasional activities like celebrating festivals or a wedding. To enable themselves to undertake these activities, Ismailis have created places for themselves in the neighbourhood. For example, Jamaat Khaana (Prayer room) to preserve cultural and religious activities in Khirkhi extension. This centre of worship is open only to the Shia Ismaili community, forbidding other Islamic sects or religions from using it. The Jamaat Khaana acts as a meditation centre for the Shia Ismaili Afghans as meditation is an important ritual of the community. The younger generations of Shia Ismailis learn about their religion and culture by engaging in various activities inside the prayer house and perform 'services' for the older generations as a pious act. It allows the Ismaili children to undertake these acts and grow up in the manner they would have grown up, had they never been forced to leave Afghanistan.

They also run the Shia Ismaili Community Centre, a place for the Shia Ismaili Council to meet and discuss matters of importance. The council has set up various sub-committees to address the needs of the members in exile. These include education committee, health committee, youth and sports committee, women portfolio, and social welfare committee. Each committee has a specific role to play in the lives of the community members. For instance, the education committee ensures that every child is enrolled in a school and meets his educational needs. Furthermore, it has an Early Childhood Development course, that helps parents chart the course of their infant's growth and plan their development.

The community ensures that displacement does not cause a complete loss of culture and identity and hence attach the highest value to their culture and religion and try to preserve them in the manner they can. In Khirkhi, the Ismailis have rented two empty apartment lots into places of meaning and utility. The identity of the community members is derived from these places and practices.

\subsection{Memory and Place-Building}

Appadurai, in his seminal work on Globalisation discusses the role of collective memory of a community in creating heterogenous places in erstwhile homogenous societies. He maintains that migrant communities create places which are rooted in their history, language, and culture and fulfil their everyday needs. These are built from the memory and diversifies the host territory. These places become significant preservers and expressions of the migrant's identity.

By engaging in various cultural, social, and economic activities, the Afghans at Khirkhi, have also created places from their memories. The most significant example of such a place is the 'Afghan Street' in the neighbourhood. This crossroad is a market lane where innumerable Afghan shops are located, run by the Afghans for the Afghans. For example, the general stores have Afghan names written in 'Dari Farsi' and contain items popular with the Afghans like the Afghan Cake or Milk Pak, Irani Cream cheese, and the like. Similarly, the food joints have names invoking memories of the homeland such as Bamiyan Burgers and sell items like beverages that are not available anywhere else but are liked by the Afghans. The market also consists of boutiques that cater to the Afghans in particular. They specialise in making clothes as per the tradition of the various regions of Afghanistan. The market is filled with Afghan tandoor baking the traditional Afghan bread that each household consumes every day. There is a saying among the refugees "Jab India aana to apna tandoor lekar aana (Bring your tandoor when you're migrating to India)."

\section{¿ isocarp}




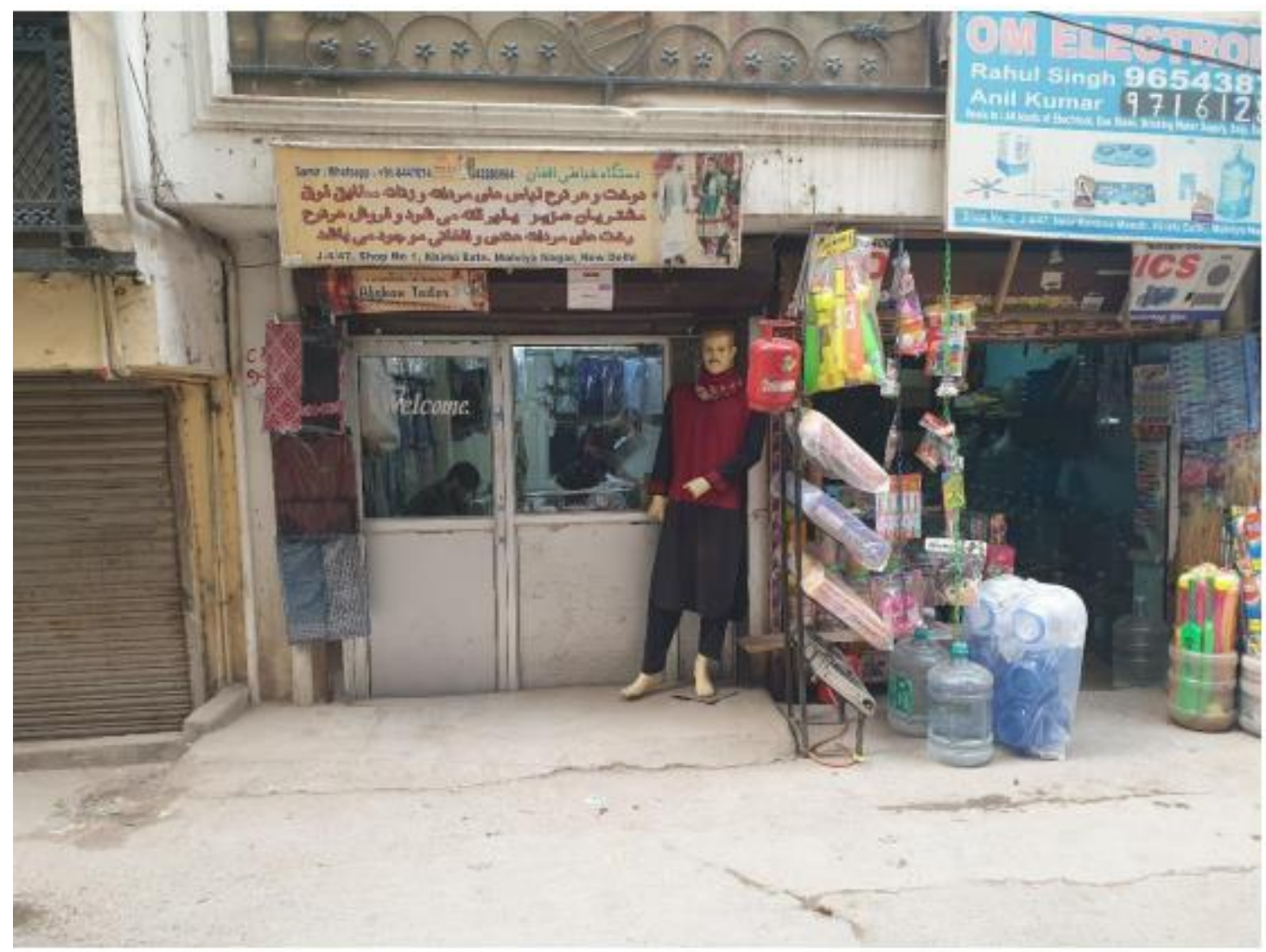

Figure 2: Afghan Boutique located on the famous 'Afghan Gulley'. Source: Field visit, Author.

The presence of such shops implies the huge demand for Afghan products and has thus established a successful trade between India and Afghanistan. Most of the products found in the market are imported and in pre-Covid times Afghan nationals established business ties with the refugees here. The entire market lane is filled with Afghan symbolism, language, and culture. In fact, the refugees realise that this market is modelled after the 'Taimani Gulley' which is in Kabul. Journalists from Afghanistan have covered this part of the city and confirm the beliefs of the refugees. The Indians, however, call it the Afghan Gulley.

Memory also plays a role in the way Afghans decorate their houses in Khirkhi. Even though the architecture of their abandoned bungalows in Afghanistan and the rented flats in Delhi do not match and the weather and environment conditions in the two countries do not meet, yet the interiors of the house remain the same. People remove their shoes before entering the house and sit on the floor lined with carpets and pillows. The traditions have continued in Delhi and these carpets are even brought from Afghanistan. They also have a portrait of prince Aga Khan in every Shia Ismaili house and shop, as is customary. Thus, the refugees live and maintain their houses as if they are still leaving in Afghanistan. 


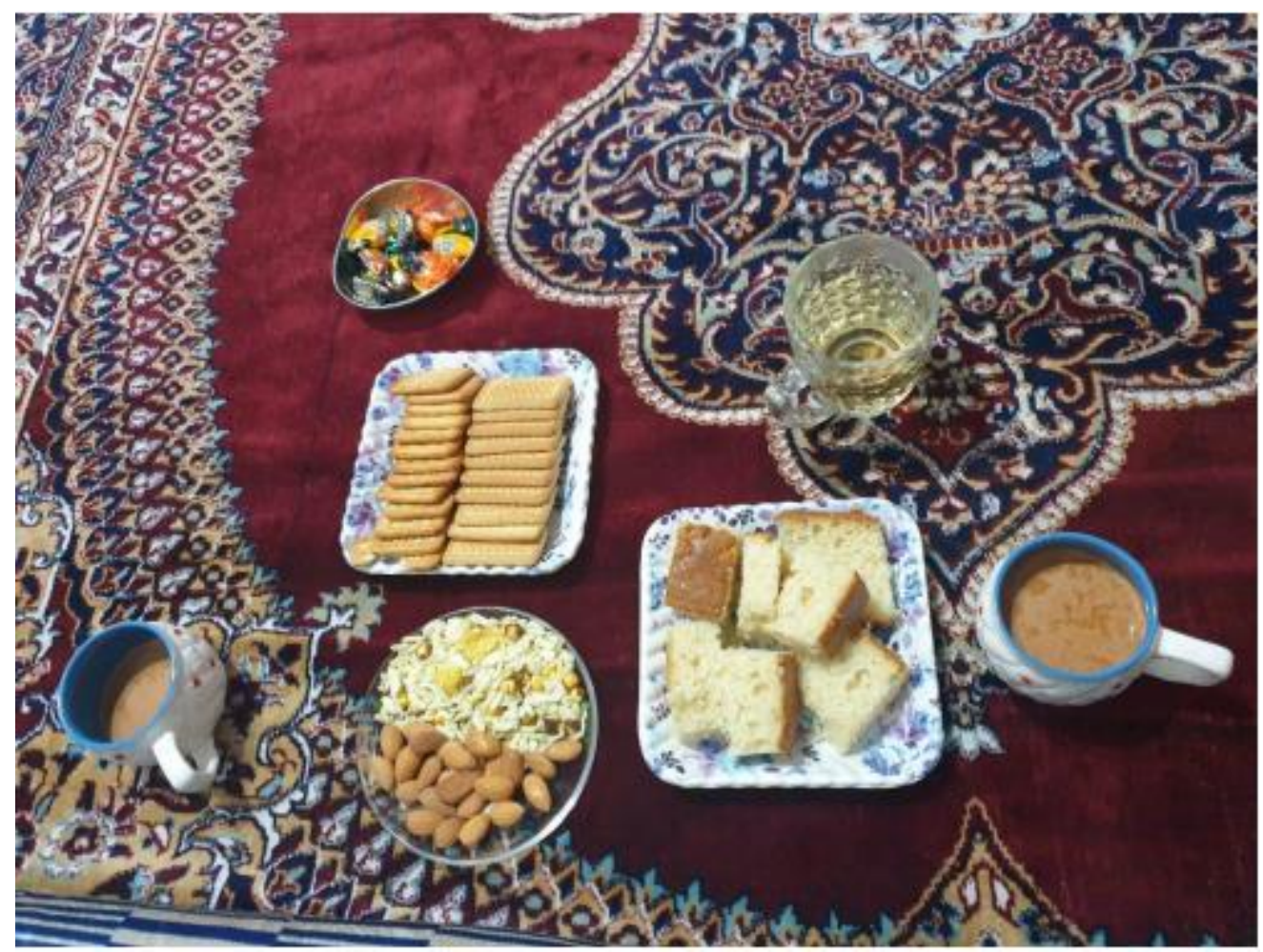

Figure 3: The local Afghan cuisine been served at an Afghan home. Source: Field visit, Author.

The places such as the Jamaat Khaana or Afghan Gulley are what Massey calls 'nodes'. They represent the diversity in society and acts as the location where cultures and identities of the migrants are preserved. The nodes change with the changing community ties and position in society and are sustained by social relations. If the Afghans decide to leave Khirkhi one day, these nodes would move away with them. The nodes are thus, adjustable to the global flows of people and communities.

\subsection{Social Capital and Place-Building}

Bourdieu defines social capital as the resources embedded in social networks which are utilised to attain more power in society. Analysing the social status of Afghans at Khirkhi through this definition shows that in comparison to other refugee communities, Afghans are better placed in society. This is because, Afghans share a history with India. Tides of refugees from Afghanistan have been given shelter in India for decades. On the other hand, refugees from other nations such as Africa have migrated recently and are yet to embed with Indian culture and society. The gap between the local Indian community and African refugees, prevents African refugees from establishing long lasting and strong ties with Indians, that the Afghans have successfully forged. These relationships enable the Afghans to create places for themselves in Khirkhi and live fuller lives in comparison to other refugees.

Even though the refugees in India does not enjoy all the rights and certain laws prevent them from accessing economical and citizenship-based opportunities, the refugees through social capital have entered the informal economy and conduct their business-like millions of Indians do. For example, refugees find it difficult to get employed in India due to lack of relevant verification documents like Aadhar card or PAN card. But, they are keen on starting a small business to sustain themselves and require a place to locate it. They rely on the social capital acquired through local ties over a couple of years within the neighbourhood. For instance, the landlords help them rent places inside the neighbourhood or find a source of procuring materials. Locals have helped Afghan youth organise themselves into artists through introduction classes such as dance workshops, craft making, and stitching centres. Through such opportunities, refugees get a platform to exhibit their talent and improve their 
skills. Artist's studios in the neighbourhood like the Khoj Studio supports the artistic abilities and aspirations of the refugees and provides them with necessary skill training and platform, thus building relations between refugee artists and art studios. For instance, Asif, a native of Khirkhi extension has several Afghan friends whom he helps by introducing them to Khoj and other opportunities across the city. Thus, social capital has been useful in creating social position and acquiring economic and cultural resources for the community.

\subsection{Place-Building: Implications and Conflicts}

As refugees are trying to make a place in the neighbourhood, conflict is a natural phenomenon that can be observed. The different ways of looking at people and culture create these conflicts among locals and refugees or among two refugee groups.

A section of Indians looks at the world and refugees from the essentialist perspective. They believe that Afghans have been uprooted from their culture and homeland. Furthermore, they should remain grateful to Indians for providing them with shelter and safety. Even though they desire more Afghans in their neighbourhood as tenants, they are wary of their cultural spread. They do not enter the Afghan Gulley and those living nearby are slowly moving to other parts of the neighbourhood where Indians dominate. The locals feel that they are losing Khirkhi's culture and identity to the Afghans.

Even though there has been no violence between Afghans and Indians, situations between the two communities often become tense. To claim social domination on the physical space inside the neighbourhood, Indian youths would sometimes drive away refugees from streets. The two communities often blame each other for the dirt and lack of cleaniliness in the neighbourhood. Indians under the fear of losing their place often looks at the refugees in a derogatory manner. To avoid any type of conflict, the Afghans try to avoid direct conflicts. They plan to relocate to another country with a more favourable refugee policy. Thus, prefer to spend their limited time at khirkhi in peace.

Looking at the neighbourhood from the refugee's lens, Khirkhi is a safe and secure place which provides opportunity to live as they wish. However, some refugee groups are better able to exercise these opportunities due to deep ties and social capital accumulation. Afghan is one such group. They, therefore, hardly characterise themselves as helpless asylum seeker and distinguishes themselves from the Somali refugees. The former feels they are culturally and materially superior to the Somalis. The latter, on the other hand, associates themselves with the Afghans and maintains that the two communities would understand each other because they have experienced the same loss. They feel that the presence of Afghan and their domination is useful for them but the Afghans view Somalis as helpless people to whom they owe no allegiance. The difference in power has led to a difference in the way the two communities treat each other.

This non-essentialist attitude towards culture and place is upheld by certain sections of the local populations that urges them to close the gaps between different communities. Primary among them is Khoj Studio and Khirkhi Collective. They acknowledge the presence of the refugees and their precarious situation in a foreign land. Thus, they organise various events to make the refugees feel more welcome. They have also organised events to bridge the gap between Indians, Afghans and other refugee groups. The efforts of the organisations have only touched a small number of people at Khirkhi while the larger communities remain uncertain about each others' cultures and intensions.

\section{Conclusion}

The paper reveals that refugees have the agency, even though limited, to shape their surrounding in the asylum country. This agency is a result of their social relations, capital, and desire to keep their culture, religion, and identity alive. 
Comparing the modern-day refugees with the earlier refugees in Delhi, following things become clear:

refugees earlier came as settlers and over the last 75 years, created permanent places that soon turned into unauthorised colonies and altered the structure of the city completely. On the other hand, Afghan refugees settled in in unauthorized colony instead of creating one because the city lacks space due to urban sprawl. They view India as place of transition to another country and therefore built places temporarily.

When they relocate, their places or nodes would move away with them and all Afghan influence will vanish. However, it shows that even a temporary stay requires serious adherence and preservation of culture and identity.

Unauthorised colonies allowed people to develop places as per their needs and requirements, since the state kept them out of their development practices. Perhaps the refugees have been able to turn Khirkhi into an Afghan enclave because of the absence of direct state controls.

These points reiterate that places are made in the reflection of those who inhabit them. The identity and culture of a place is akin to the identity and culture of the people. Thus, refugees and migrants have been able to transform places wherever they go. The Afghan enclave of Khirkhi is a node in time, which may influence some other city in the future.

\section{References}

Appadurai, A. (n.d.) 'Modernity at Large: Cultural Dimensions of Globalisation (Vol. 1)', Minneapolis: University of Minnesota Press.

Bourdieu, P. (1986) 'The Forms of Capital' in J. G. Richardson. Handbook of Theory and Research for the Sociology of Education. Greenwood, pp. 241-58.

Darling, J. (2016) 'Force migration and the city: Irregularity, informality, and the politics of presence', Progress in Human Geography, 41(2), 178-198. Available at doi:10.1177/0309132516629004 (Accessed: 13 March 2021)

Doreen, M. (1991) 'A Global Sense of Place', Marxism Today, pp. 24-29.

Dupont, V. (2005) 'Residential Practices, Creation and Use of Urban Space: Unauthorised Colonies in Delhi' in E. M. Hust. Urbanisation and Governance in India. New Delhi: Centre de Sciences Humaines, pp. 311-341.

Field, J., Tiwari, A., and Mookherjee, Y. (2017) 'Urban Refugees in Delhi: Identity, entitlements and wellbeing', London: IIED.

Gupta, S., and Balasubramaniam, M. (2019) 'From Refuge to Rights: Majnu ka Tilla Tibetan Colony in New Delhi', kritisk etnografi - Swedish Journal of Anthropology, 2(1-2).

Kumari, A. (2013) 'Delhi as Refuge: Resettlement and Assimilation of Partition Refugees', Economic and Political Weekly, 48(44), pp. 60-67.

Malkki, L. (1992) 'National Geographic: The Rooting of Peoples and the Territorialization of National', Cultural Anthropology, 7(1), 24-44. Available at http://links.jstor.org/sici?sici=08867356\%28199202\%297\%3A1\%3C24\%3ANGTROP\%3E2.0.CO\%3 B2-B (Accessed: 20 March 2021)

Mehra, D. (2013) 'Planning ca. 1939-159', South Asia: Journal of South Asian Studies, 36:3, 354-374. Available at: doi:10.1080/00856401.2013.829793. (Accessed: 15 April 2021)

Roy, P. (2018) 'A Case Study of Refugees in Towns, Delhi, India', Friedman School of Nutrition Science and Policy, Feinstein International Center.

Sharma, M. (2009) 'Refugees in Delhi', Working Paper, No 229, Centre for Civil Society.

Sundaram, R. (2010) 'A city of order: The Masterplan' in Sundaram.R. Pirate Modernity: Delhi's media urbanism. Routledge, pp. 28-66. 
Tiwari, A. D., Field, J., and Mookherjee, Y. (2017) 'Urban refugees in Delhi: Refugee networks, faith and well-being', Working Paper, IIED, London. 